\title{
Um olhar sobre a mudança de sentido e o sentido da mudança na alfabetização angolana
}

Marcelino Mendes Curimenha ${ }^{1}$

\section{Resumo}

Este artigo pretende compreender a mudança de sentido e o sentido de mudança na alfabetização do Ensino Primário de Angola, provocado pelas transformações políticas, sociais e econômicas, assim como as reformulações das políticas educativas produzidas pelas reformas curriculares que aconteceram a partir da década de 1970 até o surgimento da nova Lei de Bases do Sistema de Educação implementada no começo de 2000. Outrossim, o estudo pontua o atual estado da alfabetização angolana e nomeia os diversos desafios que Angola vem enfrentando após a independência nacional para construção de uma população alfabetizada por meio de produção dos sentidos que estabelecem à gestão social. Para isso, é utilizada a pesquisa qualitativa por intermédio da análise documental, na medida em que tais arquivos, enunciados e fragmentos como leis, decretos e estudos, de diferentes autores interdisciplinares, permitem percorrer os desdobramentos das formações discursivas a respeito das mudanças e seus sentidos na concepção de alfabetização durante o período colonial, independência nacional e o surgimento da paz após os conflitos armados.

\section{Palavras-chave}

Alfabetização. Currículo. Angola. Lei de Base do Sistema de Educação.

1. Doutorando em Educação por na Universidade Estadual de Campinas, São Paulo, Brasil. E-mail: curimenha@ hotmail.com. 


\title{
A look at the change of sense and the sense of change in angolan literacy
}

Marcelino Mendes Curimenha*

\begin{abstract}
This article intends to understand the change of meaning and the sense of change in primary school literacy in Angola, as evidenced by the political, social and economic transformations as well as the reformulations of the educational policies produced by the curricular reforms that took place from the 1970 s to the emergence of the new Basic Education System Law implemented in the beginning of 2000. The study also analyzes the current state of Angolan literacy and identifies the various challenges that Angola has been facing after national independence to build a literate population through production of the meanings that establish to social management. For this, qualitative research is used through documentary analysis, insofar as such files, statements and fragments as laws, decrees and studies of different interdisciplinary authors allow us to go through the unfolding of the discursive formations regarding the changes and their senses in the conception of literacy during the colonial period, national independence and the emergence of post-conflict peace.
\end{abstract}

\section{Keywords}

Literacy. Curriculum. Angola. Basic Law of the Education System.

*PhD student in Education, State University of Campinas, State of São Paulo, Brazil. E-mail: curimenha@hotmail. com. 


\section{Introdução}

O processo de educação e formação humana em Angola é uma história recente. Embora desconfortável com essa continuidade discursiva, é comum se afirmar, no meio acadêmico, que a alfabetização em Angola ${ }^{2}$ começou a ser discutida apenas na década de 1970. Pode-se chegar à conclusão provisória de que mesmo depois dessa data os acontecimentos posteriores não foram tão animadores. A alfabetização sempre foi pensada visando o regulamento cultural, a construção da angolanidade e de uma sociedade qualificada para o mercado de trabalho.

No entanto, a alfabetização também se tornou uma ferramenta de resistência contra os discursos coloniais cujo ensino não estava voltado para os angolanos autóctones. Não só a alfabetização serviu como instrumentalização de emancipação do sujeito, mas outros mecanismos foram também utilizados, tais como: "a produção literária de protesto; denúncias escritas por intelectuais; diferentes e divergentes movimentos sociais e políticos de luta pela liberdade; greves; desobediência civil; e, também, a musicalidade" (ALVES, 2003, p. 1). Sou propenso a salientar que a musicalidade se apresentou como um instrumento de alfabetização mais eficiente porque alcançava as classes sociais mais carentes, que não tinham acesso à escola, e trazia consigo conhecimentos que contribuíram para a reflexão sobre identidade, cultura, sentimento nacionalista, a manutenção do tradicionalismo africano, as definições da angolanidade e as formações discursivas a respeito do regime colonial. Neste contexto, Alves (2003, p. 1) argumenta que: "a música popular urbana auxiliou na construção de uma consciência nacionalista, contribuindo para a resistência e a luta anticolonial". Retomando as formações discursivas coloniais, essa educação definia a sociedade africana como uma população de "estado primitivo dos negros", antropologicamente "tratados como inferiores e, não raramente, tidos e havidos como parentes próximos dos primatas ou antropoides, portanto, bem pouco dignos do nome de homens" (NETO, M. 2005, p. 34). Entretanto, tal pensamento introduziu a noção de que o sujeito negro angolano não tinha condições cognitivas e capacidade intelectual para construir habilidades profissionais que possibilitassem o exercício de determinado trabalho que exigisse uma carga elevada de racionalidade. Martins (1920), um dos reprodutores desses discursos, tecendo suas análises dentro do escopo do darwinismo social, era categórico nas suas afirmações, pontuando que até determinando ponto o negro angolano trabalhava sim, mas:

Não por hábito, por instinto e com o fito de uma capitalização ilimitada como o europeu. Trabalha, sim, mas agrilhoado pela necessidade imediata: e as necessidades do negro são curtas, e satisfaz-se com pouco. Não abandona a liberdade e a ociosidade, para ele felizes condições de vida selvagem, pelo trabalho fixo, ordinário, constante, que é dura condição da vida civilizada. (MARTINS, 1920, p. 290).

Esse discurso colonial determinou o gerenciamento da população angolana impossibilitando a distribuição da educação para todas as classes sociais. Com isso houve

2. Angola situa-se na costa ocidental de África, possuindo fronteiras com a Namíbia, Zâmbia, República Democrática do Congo e República do Congo. Tem uma população de quase 25 milhões de habitantes, sendo o grupo étnico o vimbundu o maior (estimado em 37 por cento), os outros são: mbundu (25 por cento), bakongo (13 por cento), mestiços (mistura de europeus e africanos - 2 por cento), europeus (1 por cento) e outros (22 por cento). A língua oficial é o Português, sendo o umbundu, kimbundu e kikongo amplamente falados. A principal religião é a Cristã (MEIJER, 2004, p. 4). 
uma redução de formação de trabalhadores qualificados. Nesse vácuo se celebrava o exercício do trabalho escravo como o mais econômico e produtivo. Não existiam razões para criação de políticas educacionais voltadas para a sociedade negra. A alfabetização era vista como desperdício se direcionada a sujeitos que apenas tinham condições de atuarem à base da força e da violência. Entre outras coisas, para os negros não era considerada necessária já que, segundo os discursos do colonialismo, a escravidão cumpria o seu papel preestabelecido. Na fala de Martins (1920):

A escravidão tinha, pois, um papel positiva e economicamente eficaz, sob o ponto de vista da prosperidade das plantações. Não basta dizer que o trabalho escravo é mais caro, e que o preto livre trabalha - fatos aliás exatos em si - porque é mister acrescentar que o preto livre só trabalha intermitentemente ou excepcionalmente; e que o mais elevado preço do trabalho escravo era compensado pela constância e permanência do funcionar desse instrumento da produção ${ }^{3}$. (MARTINS, 1920, p. 219-220).

Logo, a sociedade angolana estava fora de cogitação na política educacional portuguesa. No estudo sobre o mito da portugalidade no ensino colonial, Gomes (2014, p. 2) aponta que "globalmente, durante o século XIX, não se encontra nenhum pensamento estruturante que dê corpo a uma política unificada de educação colonial". Outros autores, como Liberato (2014) e Nguluve (2006), também pontuam a mesma assertiva tratada por Gomes (2014, p. 2), de que no período do governo colonial a instrução pública da educação primária passa a ser estruturada em níveis "elementar e complementar, sendo eles dirigidos às populações "evoluídas". A população evoluída, mencionada por Gomes, é uma referência a uma parcela menor da sociedade angolana que representava os angolanos brancos de origem portuguesa, os mestiços e os grupos de angolanos nativos (negros) que se apropriavam dos instrumentos e recursos coloniais, como: a língua, o comércio, os espaços privilegiados da vida política e a residência na capital ou nos espaços urbanos estratégicos das centralidades citadinas. Para além dessas escolas, cogitavase ainda sobre a instauração das Escolas Rudimentares, destinadas, desta feita, às populações indígenas" (GOMES, 2014, p. 2).

Essa parcela da população era conhecida como os assimilados, angolanos europeizados. "A figura do "assimilado" foi, desse modo, concebida para ser um tipo intermédio entre os brancos e os indígenas" (LIBERATO, 2004, p. 1.009), uma oposição contrária àqueles que eram considerados como gentes do mato, da periferia, traduzindo no dialeto costumeiro: os dos Musseques ${ }^{4}$ ou dos Kimbus.

\section{A era das mudanças}

Dois momentos marcaram a história da alfabetização angolana no período entre 1975 a 2002. Vale frisar que historicamente falando, Angola sempre foi um ambiente reconhecido pela instabilidade política, de trabalho escravo, do regime colonial e das constantes guerras civis pós-independência entre diferentes grupos ${ }^{5}$ beligerantes. Estes elementos desestabilizaram as infraestruturas do país, provocando a redução de acesso aos recursos primordiais, como educação, saúde e

3. As principais exportações de Angola são o petróleo, diamantes, minerais, café, peixe e madeira (MEIJER, 2004, p. 4).

4. Musseque ou Kimbu são as cidades do Interior de Angola. Esses musseques e kimbus reúnem certas características distintas, como o dialeto como a língua regional, a manutenção e a vivência das culturas tradicionais africanas, com pouco acesso às tecnologias contemporâneas e à escolarização. Além disso, a principal fonte de subsistência são a agricultura, a pesca, o comércio e a produção de utensílios tradicionais.

5. Resumidamente, os agentes políticos desses conflitos foram a FNLA (Força Nacional de Libertação Nacional), 
saneamento básico. O primeiro momento se deu com o surgimento do Decreto no 60, de 19 de junho de 1976, que criou o Ministério da Educação e Cultura, contemplando na sua estrutura "uma Direção Geral do Ensino que compreendia entre outros, o serviço de Alfabetização e Formação Permanente, com a competência institucional de implementar planos, programas e projetos com o objetivo de erradicar o analfabetismo". (MENDES; ALVES; CARVALHO, 2005, p. 1.009). Em vista disso, inaugurou-se a segunda fase, ou seja, o segundo momento que instalou a luta contra o analfabetismo, tendo como ponto crucial o período de 23 a 29 de outubro de 1977, data em que se produziu, em Luanda, no Museu de História Natural, "uma resolução que orientava o governo a iniciar uma alargada Campanha Nacional de Alfabetização, em que se declarava a alfabetização como um ponto prioritário para o desenvolvimento político, económico e social" (MENDES; ALVES; CARVALHO, 2005, p. 1.009).

Valeacrescentar um lacônico mapeamento cronológico do processo de reconstrução do sistema educativo e as implementações da reforma curricular. Um dos pontos cruciais na história educacional foram as grandes afluências que aconteceram na década de 1970, das diversas populações rurais às escolas. O Instituto Nacional de Investigação e Desenvolvimento de Educação (INIDE) afirma que "se em 1974 estudavam cerca de meio milhão de angolanos, em 1980 esse número superava os 1.8 milhões" (INIDE, 2003, p. 5). O alargamento dos conflitos bélicos é apresentado como um dos possíveis impeditivos à continuidade dos indicativos, afetando os Musseques com a destruição das escolas.

O ano de 1986 é marcado pelo diagnóstico realizado pelo Ministério da Educação a respeito do estado da educação por meio de pesquisas e levantamentos de dados para dimensionar as necessidades que ela demanda. Com base nesse estudo, chegouse à conclusão da necessidade "de uma nova reforma educativa e foi então possível traçar suas linhas gerais. Em 1990, Angola envereda por um sistema político multipartidário, o que acarretou mudanças na política educativa" (INIDE 2003, p. 5). A migração do monopartidário para o multipartidário exigiu as primeiras eleições democráticas no país em 1992. O Movimento Popular de Libertação de Angola (MPLA) sai vitorioso, e a oposição alegou fraudes nas urnas, por conseguinte se prenuncia o retorno da guerra civil. As marcas dessa nova etapa dos confrontos armados espalharam-se para os diversos setores da nação, principalmente educação, saúde e desenvolvimento econômico. Dados do INIDE (2003) relatam que: Em 1992, a situação piora, estimando-se que o número de crianças em idade pré-escolar ultrapassa os dois milhões, mas somente 1\% dessas crianças tem acesso ao ensino. No ano letivo de 1994/95 foram matriculadas cerca de 101 mil crianças, o que equivale a uma taxa bruta de matrículas na ordem dos 15\%. A população em idade escolar, dentro do sistema escolar, dos 6 aos 14 anos, é de 4.290.000 e fora do sistema é de 2.020 .442 , o que representa $41,3 \%$. No

UNITA (União Nacional da Independência Total de Angola) e o MPLA (Movimento Popular de Libertação de Angola). Além desse seleto grupo houve outros, mas de pouca relevância no cenário político. Todos eles surgiram nas efervescências dos movimentos revolucionários na década de 1950 contra o regime colonial. No entanto, após a independência de Angola tais grupos entraram em conflitos armados com intervenções e influencias de forças internacionais, como a União Soviética, Cuba, África do Sul e Estados Unidos. O cenário agora era outro, a luta contra o escravagismo se transformou na luta pelo poder, diamantes, petróleos e outros recursos naturais que Angola possui. A vitória do MPLA significou sua consolidação no poder no país. Mantém-se no Governo desde a independência com um preço alto (de sangue e petróleo) travando constantes guerras entre os dois movimentos políticos. Seu regime, marcado por intolerância, genocídio, autoritarismo e corrupção permanece até os dias atuais (2019). 
ano letivo de 1996, da população angolana em idade escolar (dos 6 aos 14 anos), cerca de $70 \%$ corria o risco de cair no analfabetismo por falta de oportunidade de acesso à rede escolar. Segundo estimativas, a taxa de analfabetismo é de $60 \%$. Em 1995, a população analfabeta com mais de 15 anos foi estimada em cerca de 4 milhões de pessoas, das quais 2,5 milhões são mulheres. Para atenuar o fraco poder de absorção da rede escolar foram criados, no ensino primário, o horário triplo e as turmas pletóricas, com 60 a 80 alunos. (INIDE 2003, p. 5). O INIDE (2003) afirma que é neste contexto, deveras adverso, que se deram os primeiros passos para a preparação da $2^{\underline{a}}$ Reforma do Sistema de Educação. Em 2001, a Assembléia Nacional da República de Angola aprovou a Lei de Bases do Sistema de Educação - Lei no 13, de 31 de dezembro de 2001 (INIDE, 2003). Mesmo com esses arranjos os sinais de melhorias eram fracos, por causa de poucos investimentos diante de um Estado preocupado em vencer e conquistar o poder a base das forças militares, alimentado por um sistema político fechado à democracia, o que resultou numa:

Insuficiência de verbas, essencialmente, para a impressão de manuais de alfabetização e de pós-alfabetização e outros materiais de apoio, os atrasos no pagamento de incentivos aos alfabetizadores, o que provoca desmotivação nos próprios e, por fim, a falta de uma estrutura adequada às exigências da erradicação do analfabetismo e da funcionalidade da educação de adultos nas Direções Provinciais da Educação. (MENDES; ALVES; CARVALHO, 2005, p. 1009).

Numa pesquisa desenvolvida por André (2017) sobre os desafios do Ensino Primário no qual as análises se estruturam a base dos depoimentos dos professores da rede pública, por meio de entrevistas, o autor nos traz diante diferentes amostra sobre a situação da educação, uma das suas entrevistadas, a professora Teresa, aponta que: "a falta de qualidade de algumas escolas, materiais básicos e infraestrutura precária estão na base dos principais problemas do ensino primário em Angola" (ANDRÉ, 2017, p. 81). Lembrando que as configurações destas problemáticas se justificam sempre dentro dos contextos bélicos que se esforçavam por constantes restruturações do sistema educativo e definia diferentes rumos para ajustarem a nova conjuntura sociopolítica. Uma delas é o abandono do sistema monopartidário, como supracitado, no ano de 1990, para o sistema político multipartidário, o que acarretou a produção de reformas curriculares (MED, 2002). Nessa época a taxa de analfabetismo já atingia $80 \%$ da população. O Ministério da Educação salienta que: A guerra em Angola sempre foi uma constante desestabilizadora e provocadora de um empobrecimento cada vez maior do Estado, das populações e da já escassa rede escolar. Grandes fluxos de população dirigiram-se para as cidades consideradas mais seguras, o que aumentou a já grande concentração de população nas capitais de certas províncias nomeadamente, Lubango, Benguela, e principalmente Luanda. Assim, mais de metade da população escolar distribuise pelas províncias de Luanda (30\%), Benguela $(11,4 \%)$ e Huíla (13\%). Nas restantes províncias, essa frequência não alcança os 10\%. A frágil e sobressaturada rede escolar do país sucumbe, essencialmente nas províncias citadas. Em Luanda, há muito que não existe a classe de iniciação. A pirâmide de população escolar no Ensino de Base de base bastante larga e topo estreito, havendo $70,4 \%$ no 1 o nível, $10,9 \%$ no 2o nível e 5,8\% no 3o nível. (MED, 2003, p. 3).

Nesta fase, buscou-se organizar diferentes programas. Antes de nomeá-los, é necessário salientar que a construção dessas políticas educacionais foi marcada, como frisou Ngaba, (2012, p. 248), "pelas políticas da CPLP e das Agências ou Organizações internacionais como a UNESCO, a UNICEF e o Banco Mundial". Por outro lado, Ferreira (2005, p. 108) lamenta 
que esses "sistemas educativos dos países africanos usam as mesmas matrizes dos sistemas educativos do antigo país colonizador". A autora ainda menciona que, em vários países do continente africano, não existe uma concepção de políticas educacionais repensadas a partir da perspectiva de africanidade, da sua cultura, das dinâmicas étnico-linguísticas e dos enfrentamentos sociopolíticos.

É o caso da Zâmbia, como é o caso de Angola e de Moçambique. Nestes países as reformas nunca conseguem se constituir como revolucionárias ou como apoiadas na matriz cultural do estado africano, mas são sempre adaptações dos modelos importados de países que servem de modelo societal e/ ou implementados nas antigas metrópoles colonizadoras. (FERREIRA, 2005, p. 108).

Embora essa inquietação levante uma problemática que condiga com a realidade dos países da África subsaariana, a autora pode, no entanto, ser acusada de injustiça histórica por não levar em conta que, nos finais dos regimes coloniais, houve um sucateamento operado pelos colonizadores que, após a constatação da emancipação dos movimentos de libertação nacional, buscaram destruir todas as infraestruturas e todos os recursos aplicados na educação, saúde, transportes, além de outros meios de subsistência produzidos durante seus governos, provocando uma enorme paralisia nacional. Aliás, os profissionais qualificados e com experiências no exercício de funções de elevados cargos estavam nas mãos dos colonizadores. Isso obrigou as nações africanas, uma vez independentes, a continuarem a manutenção dos mesmos sistemas de seus opressores, já que não havia indivíduos autóctones que correspondessem aos pré-requisitos cognitivos e de qualificação especializada. Por exemplo, o próprio
Agostinho Neto (1975), líder da revolução para independência nacional e primeiro presidente de Angola, desde 1975 até 10 de setembro de 1979, data da sua morte, aponta que era:

Evidente que numa primeira fase a nossa economia se ressentirá com a falta de quadros. Para responder a esta carência será elaborado um plano expedito de formação de quadros nacionais, ao mesmo tempo em que se apelará para a cooperação internacional nesse domínio. As nossas escolas, a todos os níveis, deverão sofrer uma remodelação radical para que possam de fato servir o Povo e a reconstrução económica. (NETO, 1975, p. 4).

Dito isso, nomeio os programas organizados pelo Ministério da Educação de Angola, notadamente: o Plano Nacional de Educação para Todos em Angola (PANEPT) para o período 2001-2015, resultado da participação do Fórum Mundial de Educação realizado em Dakar no país de Senegal durante os dias 26 a 28 de Abril de 2000. Os pressupostos das recomendações da Declaração de Dakar foram elaborados a partir da Declaração Universal dos Direitos do Homem e da Convenção sobre os Direitos da Criança. Logo, o Ministério da Educação planejou estratégias de desenvolvimento da Educação Para Todos em três fases, designadamente: a fase de Emergência (2003-2006), a fase de Estabilização (2007-2011) e a fase de Desenvolvimento (2012-2015). O PAN-EPT se fundamenta em seis pilares, nomeadamente: cuidados e educação na primeira infância, educação primária universal, habilidades de jovens e adultos, alfabetização de adultos, paridade e igualdade de gênero e, finalmente, a qualidade da educação. Outro programa implementado para colmatar a elevada taxa de analfabetismo é a Alfabetização e Aceleração Escolar $(\mathrm{PAAE})^{6}$, projetado pelo Centro

6. O PAAE é um programa de alfabetização e aceleração escolar. É um programa do Governo angolano que tem como objetivo alfabetizar os adultos bem como acelerar as aprendizagens de jovens e adolescentes que por várias razões não tiveram acesso ao ensino primário. Poder-se-á dizer que é um programa que está aqui para 
Nacional de Alfabetização. Ademais, emergiu recentemente a implementação do Plano Estratégico para a Revitalização da Alfabetização (2012-2017) que propõe alternativas para se alterar o quadro da educação angolana.

Em vista disso, a alfabetização pode ser pensadacomoconjuntodearranjoseducacionais, fulcrais e emergentes nas agendas das leis das diretrizes de bases nas reformas curriculares, ocupando a centralidade dos interesses do Estado no ramo da formação e constituição de sujeitos normativos. O texto, por exemplo, do currículo do Ensino Primário, desenvolvido pelo Instituto Nacional de Investigação e Desenvolvimento da Educação (INIDE), delimita os princípios gerais de intervenção educativa no processo de formação humana. $\mathrm{E}$, pensa que:

O pronunciar-se sobre a natureza, funções e características da educação escolar supõe, implícita e explicitamente, pronunciar-se sobre o modelo de sociedade para cuja formação se quer contribuir e o modelo de pessoa e cidadão que se pretende formar. (ANGOLA, 2013, p. 16).

O documento curricular recorre ao modelo enunciado no Artigo 10 da Lei de Bases do Sistema Educativo. Esse documento define o tipo de sujeito a ser formado. Esse sujeito precisa ser integral em "personalidade com vista à consolidação de uma sociedade progressiva e democrática." (ANGOLA, 2001). Com isso, a LBSE terminou cincos objetivos principais:

Desenvolver e aperfeiçoar o domínio da comunicação e da expressão; aperfeiçoar hábitos e atitudes tendentes à socialização; proporcionar conhecimentos e capacidades para desenvolver as capacidades mentais; estimular o espírito estético com vista ao desenvolvimento da criação artística; garantir a prática sistemática de educação física e de atividades gimnodesportivas (educação física) para o aperfeiçoamento das habilidades psicomotoras. (MED, 2003, p. 3).

Com a reforma do sistema educativo de 2001, a alfabetização passou a ser mais do que apenas a aprender a ler, escrever e se expressar de forma correta. Embora no Decreto Presidencial no 17/11, lei essa que surgiu no período da reforma curricular implementada a fim de direcionar os docentes e trazer as definições da dinâmica da educação básica, coloca a alfabetização a partir de duas estruturas principais. Na primeira, define-se a estrutura curricular que acompanhou os anos de 1989 até 2001, período da independência e guerra civil, e que a alfabetização acontece por meio de aquisição da leitura, da escrita e da representação do sistema numérico. $\mathrm{E}$, na segunda estrutura curricular, abrangendo os períodos de 2002 até os anos de 2012, estende-se à pós-alfabetização, uma tentativa de avanço da primeira estrutura. Aqui (na pós-alfabetização), pretende-se consolidar e ampliar as competências educativas fundamentais, o que equivale à conclusão da $6^{\underline{a}}$ classe do Ensino Primário Regular.

\section{Estrutura da Educação Básica}

O Sistema de Educação de Angola possui três níveis de ensino, designadamente: o Ensino Primário, o Ensino Secundário e o Ensino Superior (Artigo 10 da Lei 13/01). Precedem esses três níveis, a Educação pré-escolar, à qual têm acesso crianças com idade até os 6 anos (Art. 51 da Lei no 13/01). A educação préescolar comporta a creche e o jardim infantil. Geralmente, é organizada por idades e culmina com o grupo das crianças com 5 anos de idade, correspondente à Classe de Iniciação em que é assegurada a preparação para o ensino sistemático no Ensino Primário (Art. 13 da Lei no 13/01). Essa classe de iniciação é obrigatória para as crianças que até os 5 anos de idade não tenham se beneficiado de qualquer alternativa educativa formal (Art. 51 da Lei no 13/01).

O Ensino Primário na Lei de Bases do

tentar ultrapassar a situação do analfabetismo da nação, desenvolvido pelo Estado educador (MENDES; ALVES; CARVALHO, 2005, p. 1.009). 
Sistema Educativo é o ponto de partida para o ensino sistemático. É obrigatório e unificado, com seis anos de duração, e assegura a preparação para a continuação dos estudos no Ensino Secundário (Art. 8o e 17 da Lei no 13/01). O Ensino Primário está dividido por Educação Regular e Educação de Adultos. O Primário da Educação Regular vai da 1a à $6^{\underline{a}}$ classe. O termo classe é equivalente ao termo brasileiro "ano", no qual se pode ingressar a partir dos 6 anos de idade (ANGOLA, Art. 17 da Lei no 13/01). A Educação de Adultos comporta a alfabetização, na qual se pode ingressar a partir dos 15 anos de idade, e é seguido da pós-alfabetização (ANGOLA, Art. 33 da Lei no 13/01). Em suma, conforme a fala de Silva (2011, p. 5) a educação angolana "obedece a um currículo nacional único, aplicável em todo o território, independentemente das especificidades culturais locais". Por fim, vale sintetizar que todo esse percurso analítico salienta o surgimento do Estado democrático, sua implicância nas alterações da política econômica, no sistema de educação, a necessidade de realização dos relatórios dos balanços do Grupo de Prognósticos do Ministério da Educação. Esses pressupostos "são alguns dos elementos que influenciaram em grande medida, o surgimento da atual reforma em curso no sistema educativo" (MICHINGI, 2013, p. 1).

\section{Alfabetização: sentidos teóricos}

Traversini (2003) tratou sobrea mobilização da alfabetização, objetivando a produção de modos de ser, de pensar e de agir compatíveis com um mundo globalizado e competitivo. A autora defendeu que o governamento do indivíduo, em processo de alfabetização, acontece por meio de um trabalho detalhado e minucioso. $E$, que envolve a valorização dos saberes locais, o resgate da autoestima, o uso de metodologias centradas no "aprender fazendo", o desenvolvimento de determinadas habilidades e competências para tornar os sujeitos alfabetizados e, ao mesmo tempo, responsáveis pela solução dos seus próprios problemas e de sua comunidade. O pensamento de Traversini, embora fale a partir do espaço brasileiro, permite pensar o contexto angolano. O texto da reforma curricular, fruto das transformações e reconfigurações sociopolíticas supracitadas (monopartidarismo para o pluripartidarismo, fim da guerra civil e a implementação da LBSE), apresenta três eixos da estrutura do processo de aprendizado, notadamente, do saber, do saber-fazer, do ser. Aqui pode ser encontrado um pressuposto daquilo que se pensa como alfabetização em Angola ou como ela precisa ser.

A própria Lei de Bases do Sistema Educativo "prevê a formação de cidadãos motivados e capazes de intervir, ativa, crítica e eficientemente na realidade que os cerca, o que implica o sucesso educativo dos alunos, particularmente os de ensino obrigatório" (ANGOLA, INIDE, 2003, p. 3). Embora a Lei de Bases destaque a formação de sujeitos críticos na educação angolana, contudo, entre as normas e as práticas sociais há uma distância gritante. No caso, por exemplo, da participação ativa dos estudantes e professores por meio do diálogo e efetivação de políticas publicas para melhoria da qualidade educacional é uma realidade distante. Não só a população é ignorada. Até mesmos os funcionários de educação não são convocados a expressarem seus pensamentos, exigirem do Governo maior investimento, prioridades nos cumprimentos dos planos nacionais de formação, na valorização da profissão docente, na construção de infraestrutura e implementação de recursos que dinamizem o trabalho docente e potencializem um aprendizado mais eficaz. Esse insucesso da falta de qualidade da educação básica é resultado de um processo histórico enraizado no sistema de centralização e hierarquia de poder que perdura desde a época colonial. Pain (2008, p. 3), cônscio desse problema estrutural, afirma que: 
A configuração do espaço público em Angola foi comandada pelo Estado desde a época colonial. Desta maneira, os severos limites impostos à participação de atores não estatais impediram a construção social de uma cultura do diálogo e ignoraram a contribuição de mecanismos promotores de coesão social, particularmente de normas sociais complementares à racionalidade do Estado e do mercado.

A história do debate em Angola ainda é recente. Embora diferentes movimentos sociais surgissem para exigir os direitos das minorias, "a conjuntura autoritária dificultava qualquer tentativa de participação por parte da população" (PAIN, 2008, p. 3). Com a máquina estatal, de natureza autoritária, herança do período colonial e remanejada pelo sistema de planejamento com bases socialistas, também teve os efeitos da tradição bantu africana que legitimava a relação vertical, de submissão aos mais velhos por meio de uma obediência servil. Trazer isso à mesa contribui para compreender porque os estudantes angolanos são involuntariamente desprovidos de vozes e participação da construção da educação e apresentam dificuldade de expressarem suas opiniões em relação ao conhecimento curricular.

Na ordem dos discursos, Foucault (1996, p.

8) tratou sobreainterdiçãodiscursiva, para oautor,

em toda sociedade a produção do discurso é ao mesmo tempo controlada, selecionada, organizada e redistribuída por certo número de procedimentos que tem por função conjurar seus poderes e perigos, dominar seu acontecimento aleatório, esquivar sua pesada e temível materialidade. [...] Em uma sociedade como a nossa, conhecemos, é certo, procedimentos de exclusão. O mais evidente, o mais familiar também, é a interdição. Sabese bem que não se tem o direito de dizer tudo, que não se pode falar de tudo em qualquer circunstância, que qualquer um, enfim, não pode falar de qualquer coisa. Tabu do objeto, ritual da circunstancia, direito privilegiado ou exclusivo do sujeito que fala. (FOUCAULT, 1996, p. 8).

Ponderar isso permite o reconhecimento de que a alfabetização angolana é discutida dentro de um espaço que tem a sua própria história - traumática - que influencia fortemente a capacidade dos angolanos de se organizarem e falarem publicamente (PAIN, 2008). Com a tentativa de golpe de Estado, em maio de 1977, protagonizado por Nilton Alves, um dos fundadores do mesmo partido (MPLA), instalaram-se crises no seio do MPLA. E isso acarretou no surgimento de um ambiente hostil ao pensamento contrário. Essa variável, além das guerras, "teve enormes ramificações para impedir o futuro crescimento da sociedade civil em Angola" (PAIN, 2008, p. 5).

Brandão (1983) ao tecer sobre a educação popular diferencia a condição de uma sociedade regida pela desigualdade, mundo que:

Obriga a pensar, na educação, a necessidade de uma estranha educação popular. Existimos dentro de um mundo social onde senhores do poder, através do Estado, decidem e definem para os "outros" (para nós) o que querem que seja a relação entre eles e os "outros" (nós). Vivemos em uma sociedade onde um Estado de democracia restrita não é o lugar coletivo do poder consensual de criar direitos, de criar por consenso as normas da vida coletiva, mas apenas é o lugar de obedecê-las. (BRANDÃO, 1983, p. 4).

Logo, a alfabetização sem intencionalidade de construir uma mente crítica se resumia numa ferramenta de preparação para o mercado de trabalho. Por outro lado, a alfabetização não deve responder apenas às demandas do mercado. Paulo Freire (1996, p. 14) acreditava que o "educador democrático não pode negarse o dever de, na sua prática docente, reforçar a capacidade crítica do educando, sua curiosidade e sua insubmissão". O Governo angolano, em vista da fraca educação colonial, buscava, de 
certa forma, sanar a ausência de profissionais qualificados. Logo, a alfabetização precisava surgir como construção de uma população que pudesse potencializar o desenvolvimento econômico e que apresentasse futuras soluções para resoluções dos problemas ou da realidade que os cercavam. Na concepção de Braga Paixão (1921), o ato de alfabetizar não deve estar relacionado somente a obter as letras que o tornam suficiente para determinada função ou utilizar as ferramentas encontradas harmonicamente nos livros didáticos. A fala do autor se caracteriza da seguinte maneira:

Pior que a multidão analfabeta é a multidão que sabe apenas ler, para dizer melhor, a multidão que julga que sabe ler, porque pegando num livro ou num jornal sabe reproduzir as palavras nele representadas. Ora ler não é isto: ler é entender, é perscrutar ideias, é desvendar raciocínios, é interpretar intenções, é reconhecer sentimentos. E a operação de ler, para o homem que sabe ler, segue-se outra, imprescindível-julgar. (PAIXÃO, 1921, p. 18-19).

$O$ que se nota, a seguir, é que a alfabetização em Angola tende a se estruturar a base de um trabalho rigoroso, a valorização dos saberes produzidos no contexto cultural do mercado. Com isso, se desvaloriza diferentes saberes e se legitima conhecimentos que constroem sentidos e constituem subjetividades. Conforme afirma a INIDE (2003, p. 3),

as crianças são o futuro da humanidade e, a sua educação depende muito dos adultos, que devem pensar nessa faceta para inculcar valores e ideias claras para que o futuro, a ser erguido pelos adultos, corresponda aos planos positivos de uma Nação ou humanidade inteira.

Logo, é possível convocar outra vez Traversini (2003) para demonstrar que a dinâmica e potencialização da alfabetização acontecem dentro de um escopo mais geral. A autora aponta que:
O processo de alfabetização institui comportamentos antes considerados desnecessários na comunidade. Da oralidade, passa-se à escrita. Consomem-se produtos antes não consumidos. Práticas naturalizamse e são tratadas como uma das formas de confirmar o sucesso dos cursos de alfabetização. No entanto, mais do que isso, elas denotam a produtividade de um programa de alfabetização na regulação de comportamentos e atitudes e na administração da vida de uma comunidade. Em síntese, por meio da escrita, da leitura e do cálculo escolar, os indivíduos alfabetizados aprendem a conhecer-se e a conhecer os outros e assimilam valores e atitudes a serem utilizados de uma determinada forma em uma sociedade alfabetizada. (TRAVERSINI, 2003, p. 13).

A Lei de Bases do Sistema de Educação (LBSE) não se diferencia tanto dos projetos de alfabetização padrão em muitos países em que a alfabetização se resume apenas na "possibilidade de decodificar textos breves e escrever algumas palavras (além de grafar quantidades e talvez as operações elementares)" (FERREIRO, 2017, p. 16). Se existe certo distanciamento com as demais leis educativas, talvez seja porque ela tenta ver a alfabetização como a formação de sujeitos para comportamentos corretos, não apenas para a obtenção de conhecimentos da língua portuguesa, matemática, mas como forma de conduzir a vida por meio de uma educação moral e cívica. Para Clarice Traversini (2003, p. 22), a "alfabetizar é, sim, ensinar a ler, escrever e calcular, mas é também uma forma de modificar comportamentos dos indivíduos tornando-os sujeitos autoconfiantes e autorresponsáveis pela sua vida". Do mesmo modo, Mariza Silva (2000, p. 1) pensa a alfabetização como:

Rito de passagem do sujeito já-falante para um novo espaço-tempo de produção de linguagemque, embora referidonecessariamente a uma língua falada, possui sua estrutura e funcionamento discursivo próprio. Trata-se de uma prática em que o sujeito se apropria - ou 
não - de um objeto histórico e simbólico - a escrita alfabética - para exercer as funções de leitor e de autor em meio a textualidade já existente, que organiza e administra uma sociedade dada, ao construir as suas instituições através de processos discursivos próprios.

Relativamente ao ritual de passagem, é possível pensar a noção do sujeito novo. No documento curricular do Ensino Primário de Angola existem três dimensões do mesmo processoformativoparaoqualosistemaeducativo de Angola presta atenção, nomeadamente a sociedade, homem e conhecimento. Isso pode ser verificado por meio do paradigma educativo e dos modelos pedagógicos que sustentam a formação do sujeito da educação angolana, ou seja, dos processos discursivos inerentes ao documento do Currículo do Ensino Primário. O texto salienta que "muito se joga no domínio da decisão política. As opções neste terreno são, em primeira instância, condicionadas (porque condicionadoras) do modelo de sociedade, homem e conhecimento que se deseja construir" (ANGOLA, 2013, p. 18). Esses elementos podem ser vistos como uma tentativa intervencionista nos modos de pensar o sujeito e como esse sujeito pode pensar.

Traversini (2003) salienta que, por meio da linguagem, o analfabetismo é "traduzido e exposto à intervenção e regulação, para isso, é preciso descrever como e onde o analfabetismo se encontra, construindo modos de torná-lo receptivo à intervenção" (TRAVERSINI, 2003, p. 41). Outrossim, Mariza Silva (2000) argumenta que é a partir de uma posição no lugar de referencialidade e literalidade que se constrói o sujeito letrado, objetivando sua ação na sociedade. Nessa mesma linha de pensamento, vale reiterar que, do ponto de vista histórico, os discursos sobre alfabetização em Angola são tramados visando cumprir igualmente o seu papel de preparação, de ritual da iniciação, de organizar o palco para que outros conhecimentos possam ser construídos. Outra potencialidade da alfabetização que se tornou um instrumento desejado é sua possibilidade na formação laboral da jovem geração a fim de contribuir para o desenvolvimento econômico. O sujeito é, então, efeito da alfabetização. Ao refletir sobre essa questão, relativamente aos discursos sobre alfabetização e processo de subjetividades na constituição do sujeito, Silva (2000) aponta que o sujeito: Neste novo espaço de produção de linguagem, apropria-se de uma forma particular da escrita, domina-a, controla-a, produz interpretações e textos próprios, responsabiliza-se pelo dito. Trata-se de uma forma de individualização em que o sujeito deve inscrever-se em um interdiscurso [...] a inscrição do sujeito na cultura letrada implica a sua filiação a determinadas formações discursivas, ou seja, as práticas pedagógicas criam condições institucionais para que o sujeito ocupe determinadas posições, a partir das quais ele 'saberá' o sentido do que ouve e diz, lê ou escreve enquanto sujeito-falante, 'saberá' o que pode e deve ser dito. A partir dessa posição, o sujeito se apresenta e representa como leitor e autor de textos que têm determinadas interpretações como evidentes. (SILVA, 2000, p. 5). Isso me leva a refletir sobre o pensamento de Foucault (1999), no último capítulo da História da Sexualidade I, no qual o filósofo trata sobre o Direito de morte e poder sobre a vida, e salienta que "agora é sobre a vida e ao longo de todo o seu desenrolar que o poder estabelece seus pontos de fixação" (FOUCAULT, 1999, p. 129). Esse poder pela vida desenvolveu-se, conforme Foucault, a partir do século XVII, exercendo o controle pelos corpos dos sujeitos, por meio de dois eixos (poderiam ser três, pensando no sujeito como objeto de saber), que se interligam - discurso e relação de poder - desenvolvendo um processo intermediário de relações. Para sua efetivação, "apresenta-se agora como o complemento que empreende sua gestão, sua majoração, sua multiplicação, 
o exercício, sobre ela, de controles precisos e regulações de conjunto" (FOUCAULT, 1999, p. 128). Não obstante, o poder sobre a vida centrou-se no corpo como máquina:

No seu adestramento, na ampliação de suas aptidões, na extorsão de suas forças, no crescimento paralelo de sua utilidade e docilidade, na sua integração em sistemas de controle eficazes e econômicos - tudo isso assegurado por procedimentos de poder que caracterizam as disciplinas: anátomo-política do corpo humano. O segundo, que se formou um pouco mais tarde, por volta da metade do século XVIII, centrou-se no corpo-espécie, no corpo transpassado pela mecânica do ser vivo e como suporte dos processos biológicos: a proliferação, os nascimentos e a mortalidade, o nível de saúde, a duração da vida, a longevidade, com todas as condições que podem fazêlos variar; tais processos são assumidos mediante toda uma série de intervenções e controles reguladores: uma bio-política da população. (FOUCAULT, 1999, p. 131). Assim como Castro (2016, p. 188) testifica, é "com efeito, tal como aparece no último capítulo de La volonté de savoir, as sociedades modernas não são apenas sociedades de disciplinarização, mas também de normalização, dos indivíduos e das populações." Por meio do exercício microfísico de podersaber sobre o corpo e a alma, Clarice Traversini (2003) salienta que, "o indivíduo age sobre si normalizando-se e produzindo um processo de subjetivação sobre seu próprio 'eu' para tornarse um sujeito útil e produtivo na sociedade contemporânea" (TRAVERSINI, 2003, p. 35).

\section{Alfabetização em Angola: que reformulações?}

De acordo com o exposto anteriormente, pode-se tomar os documentos curriculares angolanos juntamente com a LBSE e prosseguir a partir dessa perspectiva. A alfabetização objetiva formar sujeitos úteis - potencializados para a produção dessa sociedade, mais angolana, mais cultural, mais econômica. A LBSE pretende ser categórica nesse objetivo, e não cessa de afirmar que a educação surge em função da alfabetização e deve acontecer por um "processo que visa preparar o indivíduo para as exigências da vida" (ANGOLA, 2001) procurando, a partir dessas exigências, desenvolver as "potencialidades físicas intelectuais, morais, cívicas, estéticas e laborais da jovem geração" (ANGOLA, 2001), fazendo isso de forma contínua e sistemática.

Em vista disso, a LBSE se utiliza do processo de alfabetização na formação do sujeito da educação angolana, objetivando a compreensão do mundo no qual se insere, principalmente no reconhecimento dos problemas nacionais. Em seguida, o sujeito precisa se inscrever numa alfabetização participativa e ativa no contexto social (ANGOLA, 2001). O sujeito precisa, além disso, conhecer a si mesmo, através da consciência pessoal e social, possibilitando o estabelecimento de melhoria na qualidade de vida, na promoção do direito e respeito à vida, à liberdade e à integridade pessoal (ANGOLA, 2001). Tudo isso requer certos requisitos de integração com todos esses elementos e, finalmente, com o mundo. Cabe aqui, de forma resumida, apresentar o sujeito analfabeto que é problematizado, articulado e incorporado dentro das preposições curriculares. Para os documentos curriculares, o analfabeto angolano possui determinado comportamento, que segundo esses discursos, não coaduna com as práticas da sociedade e do Estado, o que faz desse sujeito um empecilho ao desenvolvimento de Angola.

A alfabetização, nesse contexto, surge como necessidade de transformação do sujeito descivilizado, aquilo que Pacavira 
(1981) denominou, em seu livro Gentes do $\mathrm{Mato}^{7}$, os matumbos. O termo matumbo, variante de matumbu (kimbundu - língua nacional), passou a designar, em Angola, um "indivíduo bastante atrasado", ainda não liberto dos costumes considerados primitivos. O matumbo também é visto como alienado, em termos de conhecimentos ditos científicos, por viver no seu "habitat natural", sem ser privilegiado com o avanço tecnológico de uma sociedade que se diz moderna. Além disso, em diferentes contextos, poderia conotar também o significado de: "selvagem; ignorante; bisonho; e numa linguagem figurada: incivil; acanhado; inexperiente" (RIBAS, 2009, p. 305). Esse termo, registrado pelos documentos portugueses, desde pelo menos o final do século XIX, serviu também para:

Designar os africanos ainda não urbanizados e era utilizado em alternância com a expressão "gentes do mato", criando-se, assim, mais uma clivagem na sociedade angolana, onde um grupo nativo secularmente instalado no litoral e no núcleo urbano da colônia se considerava superior aos angolanos vindos do interior ou lá residentes. (NASCIMENTO, 2013, p. 16).

Essa posição discursiva reducionista se refere a uma forma de individualização "em que o sujeito deve inscrever-se em um interdiscurso - memória do dizer - marcado por um tipo de abstração que determina uma forma de racionalidade: jurídica, religiosa, moral, política, científica" (SILVA, 2000, p. 4). A autora ainda reitera que nesse processo de inferiorização, o sujeito deve inscrever-se em uma cultura específica:

A letrada, racional e urbana, ocupar uma posição enunciativa histórica: a de leitor e de autor. Nessa forma de individualização (uma unidade assegurada pela consciência), um sujeito moral (responsável por seus atos) é o complemento necessário do sujeito de direito (aquele que tem uma identidade socialmente reconhecida e reconhecível) (SILVA, 2000, p. 4).

O Decreto Presidencial n.․ 17/2011 que apresenta o Estatuto do Subsistema do Ensino Geral constitui o "fundamento do conjunto do sistema de Educação e Ensino na República de Angola para conferir uma formação integral, harmoniosa, e uma base sólida e necessária à continuação de estudos nos subsistemas subsequentes" (ANGOLA, 2011), promulga-se o caminho que o Estado pretende criar para solucionar, primeiro, a falta de acesso à educação que afeta a parcela maior da sociedade angolana, em seguida, educar de maneira intensiva e qualitativa, com o propósito de cumprir as diversas metas de transformar o sujeito analfabeto em um sujeito letrado, capaz de "produzir sentidos - velhos e novos - para as suas coisas e as coisas" (SILVA, 2000, p. 1), se assim se pode dizer, de Angola.

Para formar, existe a necessidade de propiciar mecanismos para essa investida. Logo, o referido Decreto, no seu Art. $3^{\circ}$, consubstancia as seguintes e principais estruturas relativas à alfabetização, notadamente:

I. Da gratuidade do ensino primário em estabelecimentos públicos não lucrativos e de solidariedade social, sendo gratuita a inscrição, a assistência às aulas e o material escolar em todos os estabelecimentos públicos, ou da rede de parceiros (ANGOLA, 2011).

II. $\mathrm{O}$ distanciamento entre as palavras (lei) e as coisas (praticidade) de Angola torna-se uma problemática para ser discutida, principalmente em relação à gratuidade em instituições

7. Gente do Mato é um termo pejorativo para desconsiderar a pessoa que nasceu no interior de Angola, em virtude de não ter acesso à educação formal e ao domínio de tecnologia. Povos da zona rural angolana utilizaram-se das possibilidades de ascensão social institucionalizadas pelo Estatuto do Indigenato (1926-1961) para constituir-se numa elite letrada, de origem rural, em Luanda. (NASCIMENTO, 2013). 
públicas motivados pelos diversos questionamentos e reclamações que são levantadas desde a educação básica ao ensino superior. É de fato gratuita a educação pública em Angola? Existe, por parte das direções escolares, a tentativa de obrigar os pais a pagarem taxas, mensalidades, compras de materiais nas escolas públicas. A revista Observatório da África (2016), por exemplo, apresenta uma leve amostra daquilo que tem sido uma prática usual no contexto angolano através duma pesquisa organizada dentro das escolas públicas da educação básica. A conclusão que se chegou foi a seguinte:

Grosso modo, as cobranças começam nas classes de iniciação e vão de 200 a 2.200 kwanzas $^{8}$, até à nona classe. Os gestores escolares dizem que é para atenuar os gastos correntes. A legislação defende a obrigatoriedade e gratuidade da educação da iniciação à nona classe. Conhecedores da ilegalidade, muitos docentes não se coíbem de receber o dinheiro diante dos repórteres. Professores que fazem parte da comissão de confirmação de matrículas afirmam estar a seguir orientações da direção do estabelecimento. Afirmam que todos, incluindo os funcionários, respeitam essas diretrizes. "Sem dinheiro, não há matrícula", diz, enquanto mostra o volume do dinheiro por baixo da capa de processos. Um dos professores diz que 200 kwanzas se destinam à compra da capa do processo e dois mil são para confirmar a matrícula. No Sambizanga ${ }^{9}$, está-se a pagar 2.200 kwanzas. Emocionado, diz desconhecer a lei que defende os interesses dos alunos no país. Já a encarregada de educação Madalena José confirmou a matrícula da filha com o pagamento de dois mil kwanzas. "Tenho de pagar, a escola está a exigir", disse. (OBSERVATÓRIO DE ÁFRICA, 2016, p. 3).
III. Da democraticidade do ensino, consubstanciado na igualdade de direitos ao acesso e frequência ao ensino, e na participação da resolução de problemas (ANGOLA, 2011).

Embora a Lei de Bases afirme tanto a democraticidade como a efetivação de direitos iguais para o acesso à educação, estudos empíricos apresentam o distanciamento entre a normatividade da lei e sua praticidade. Mpinda Simão, Ministro da Educação, no texto "Angola: Exame Nacional 2015 da Educação para Todos", reproduz o posicionamento legislativo argumentando que "os nossos esforços têm sido orientados e concentrados na concretização da política educativa do país cuja visão estratégica está claramente refletida em três pilares, sendo: o acesso, a equidade e a qualidade educativas como prioridades" (ANGOLA, 2014). Além disso, acrescenta que "o compromisso do Estado Angolano para uma Educação de Qualidade para Todos e que nos engajemos todos com a convicção de que a Educação é um problema da Nação" (ANGOLA, 2014). No entanto, uma parcela expressiva da população angolana não tem acesso a escola e aqueles que o têm, não conseguem se manter pelas diferentes situações socioeconômicas. Segundo Ferreira (2005, p. 115):

A chegada recente à cidade e a necessidade de sobreviver, não permite a parte da população ter acesso à escola, dado que não sobram recursos para libertar as crianças do trabalho ou da mendicidade e muito menos para pagar a entrada na escola oficial ou a entrada e a mensalidade num dos múltiplos tipos de escolas privadas.

IV. Do pluralismo de concepções andragógicas, assim como a coexistência

8. O Kwanza é a moeda angolana. Atualmente 1,00 dólar norte americano equivale a 315,26 Kwanzas.

9. Um dos municípios mais antigos da Província de Luanda. 
de instituições públicas, privadas e não lucrativas - rede de parceiros (ANGOLA, 2011).

V. Da interdisciplinaridade e da vinculação entre educação escolar, o trabalho, as práticas socioculturais e o mundo do aluno adulto (ANGOLA, 2011).

VI. Da igualdade de condições para o acesso e permanência no processo educativo, no que se refere à diversidade geográfica, social, econômica, cultural e étnico-linguística, das comunidades a que se destina (ANGOLA, 2011).

Por ser um Decreto que coordena a formação de sujeitos (adultos) que não foram privilegiados com a educação no período infantil, o texto se direciona à base de um trabalho que acontece por meio da formação, com a intenção de recuperar o tempo perdido de adolescentes, jovens e adultos, a fim de aumentar o nível de conhecimentos gerais mediante a eliminação do analfabetismo juvenil e adulto, literal e funcional (ANGOLA, 2011). Da mesma maneira, o projeto curricular que permeia esse texto é a formação pela aquisição da leitura, da escrita e da representação do sistema numérico.

\section{Fases da alfabetização angolana}

OquetambémchamaaatençãonoDecreto no 17/11, é seu interesse pela "alfabetização como Segurança de si e Preparação para o Futuro. Em seguida, a alfabetização como Educação Sexual (Prevenção Sexual)" (ANGOLA, 2011), e seu interesse em uma alfabetização que se importa com o cuidado do corpo (prevenção de riscos). É por meio da reforma curricular, assim como dos documentos curriculares que daí se operacionalizam, que se sustenta a possibilidade de fazer certas tentativas para a criação de verdades acerca da alfabetização. $\mathrm{O}$ foco da alfabetização se descentraliza, invertese a necessidade de ensinar para aprender a ler e escrever, e opera-se na catalogação de todas as variações de sujeitos alfabetizados. Não se trata mais de transmitir os conteúdos dos programas escolares, mas da fabricação de sujeitos por meio desses conteúdos. Não se trata mais de ponderar sobre o que seria a verdadeira e boa alfabetização, mas de fazer com que determinados sujeitos possam ocupar espaços dos discursos considerados verdadeiros.

A seguir, examinarei esses dois interesses ou elementos que mencionei anteriormente, do Decreto no 17/11 do Ensino Primário, que emergem de forma recorrente nos documentos da reforma curricular. Ambos têm por objetivo uma forma de alfabetizar, para saber-se, à base de demonstrações de "atitudes corretas de regras e normas de conduta, de atitudes de respeito pelo seu corpo, pela saúde e pela higiene" (ANGOLA, 2013). Esse texto faz alusão ao Art. 17 da LBSE, em que o Instituto Nacional de Investigação e Desenvolvimento da Educação (INIDE) salienta que os valores éticos, cívicos, culturais e outros que se "pretendem transmitir através do processo de ensino, permitirão que as novas gerações sejam dotadas de conhecimentos lógicos, condição necessária para a resolução de questões problemáticas próprias da vida individual e coletiva" (ANGOLA, 2013). Já no Decreto no 17/11, a alfabetização visa "possibilitar situações de aprendizagem que favoreçam o desenvolvimento da autoestima, de um projeto de futuro e de esperança" (ANGOLA, 2011).

$O$ sujeito alfabetizado deve ser caracterizado a se prontificar para atravessar fases - que implicam mudanças para o futuro. Essas fases, no caso de Angola, podem ser nomeadas, primeiro, pelo atravessamento que o analfabeto realiza para o mundo das letras e da tecnologia. Outra fase é a transição que se perscruta a sua formação como possibilidade econômica; aqui a alfabetização serve para preparação do mercado 
e a linguagem que destacadas são aquelas que apresentam uma concepção neoliberal como proposta educacional voltada ao mercado de trabalho por meio de formação e qualificação de trabalhadores. Aqui, a alfabetização tende a retirar, por meio de recursos humanos formados, o estado do subdesenvolvimento para o avanço econômico. Por conseguinte, a última fase visa formar o sujeito adaptável aos contornos e transformações que se sucedem de forma dinâmica no tecido sociocultural.

\section{O surgimento de outros sentidos: o corpo alfabetizado}

Acrescento outro elemento sobre a constituição do sujeito angolano no saber da alfabetização, e, para isso, retorno outra vez ao Decreto no 17/11, com a pretensão agora de tratar sobre a constituição do sujeito mediante uma alfabetização que levanta temáticas voltadas à sexualidade, assim como uma educação sexual que ensina temas como: a gravidez, o aborto, métodos contraceptivos, a importância da camisinha e doenças sexualmente transmissíveis. O texto salienta que alfabetizar é dinamizar um ambiente de aprendizagem que valorize a equidade, previna os casamentos e gravidezes precoces, maternidade/paternidade na adolescência, exploração e abuso sexual e desencoraje os estereótipos de gênero (ANGOLA, 2011).

O fórum de discussão, desenvolvido pelo Fundo das Nações Unidas para a Infância (UNICEF, 2015), designado "Jango Casamento Infantil", realizado em Luanda, demonstra duas das razões que levam à implementação do processo de alfabetização como conjunto de comportamentos a respeito do cuidado sobre gravidez precoce, maternidade/paternidade: em primeiro lugar, as consequências que acarretam a "desistência escolar" e, em segundo lugar, as "consequentes dificuldades futuras em conseguir emprego são outras das influências negativas, o que também apresenta efeitos desfavoráveis para o desenvolvimento do país" (UNICEF, 2015, p. 3). Chipalanga (2014) salienta que as associações/colaborações de diversas entidades da sociedade angolana devem repensar as políticas de educação e saúde, visando:

Não só maior e melhor sensibilização dos adolescentes, com programas distintos, tais como: educação para o ambiente, programas de melhoramento da vida na comunidade, de educação sexual nas escolas, nas famílias, nas igrejas, melhorar e expandir os programas de saúde reprodutiva, entre outras ações poderiam revelar-se produtivas na redução das taxas de gravidez na adolescência. Por outro lado, uma maior atenção às famílias carenciadas também se poderia revelar um bom contributo para esta causa (CHIPALANGA, 2014, p. 36).

O cuidado por uma alfabetização que pretenda enfatizar o controle do corpo se realiza da seguinte forma: primeiro, uma educação que vise às prevenções contra 0 uso de drogas se tornou prerrogativa nos textos da alfabetização do Ensino Primário, fundamentados nos efeitos ou consequências que delas podem resultar. $\mathrm{O}$ interesse por esse projeto encontra-se no argumento preconizado pela LBSE de que alfabetizar é "fomentar a criação de um projeto de vida que oriente a prevenção de condutas de riscos associados ao consumo de drogas." (ANGOLA, 2011 p. 167).

Por outro lado, segundo a mesma lei do sistema educativo, alfabetizar pode ser também entendido como uma forma de melhorar o comportamento sexual, no sentido de prevenções, como quanto ao casamento e gravidez precoces, objetivando dessa forma manter o sujeito saudável. Por isso, o documento curricular do Ensino Primário (ANGOLA, 2013) visa também, em vários momentos, produzir sujeitos que conheçam e dominem seus corpos, controlando as suas funções e a importância da 
higiene e da conservação da saúde.

\section{Considerações finais}

Neste trabalho procurei analisar as principais mudanças no processo de (re) construção da alfabetização em Angola e compreender quais sentidos se configuravam a partir das formações discursivas que emergiam dentro de um contexto delimitado e específico. No período colonial discutiu-se que a alfabetização em Angola se definia pela noção reducionista da população angolana, normalizados como intelectualmente incapazes de alinharem-se aos saberes protagonizados pelos currículos das escolas do regime português. Nesse processo, selecionou-se e distribuiu-se, de modo limitado, a escolarização para os angolanos autóctones resumindo no exercício do trabalho manual para manutenção do trabalho escravo. Aqui a alfabetização não se coadunava com o perfil da população angolana, reconhecida como naturalmente primitiva.

Com o surgimento dos movimentos sociais, tendo seu apogeu na década de 1970, a alfabetização se torna uma ferramenta de emancipação, inovação, reformulação dosistema educativo e de asseguramento de eficiência para o desenvolvimento econômico. Nessa fase as mudanças que a alfabetização procura operar se faz num sentido de emergência, resultado do nascimento duma nova República. Para isso foram construídas diversas politicas educativas visando alcançar toda população angolana que estava ausente das escolas. Os retrocessos que serviram como impeditivo para o crescimento qualitativo e quantitativo da alfabetização foram os conflitos armados, o sistema político centralizado conduzido por um Governo autoritário que dificultou a participação da sociedade civil. Nesse período a alfabetização tinha um sentido de obtenção de conteúdos predeterminado por um plano nacional unificado e intransigente.

Na última fase, que começa no período da década de 2000, a alfabetização recai não apenas numa educação voltada para o mercado de trabalho, mas se volta também para o corpo da população que participa desse processo. Aqui a alfabetização ganha outro sentido, se pensa e se organiza saberes sobre uma educação para vida saudável.

\section{Referências}

ALVES, A. P. Angola: musicalidade, política e anticolonialismo (1950-1980). Revista Tempo e Argumento, Florianópolis, v. 5, n. 10, 2013. Doi: 10.5965/2175180305102013373.

ANGOLA. Decreto no 17/11. Assembleia Nacional de Angola, Luanda, I SÉRIE, n. 6, 11 jan. 2011. ANGOLA. Instituto Nacional de Investigação e Desenvolvimento da Educação (INIDE). Currículo do ensino primário: reforma curricular. Luanda: Editora Moderna. 2013.

ANGOLA. Ministério da Educação (MED). Caracterização global do contexto angolano e respectivo sistema educativo. Luanda: INIDE, 2003.

ANGOLA. Ministério da Educação (MED). Lei no 13/01. Lei de Base do Sistema de Educação (LBSE). Luanda, 2001.

ANGOLA. Ministério da Educação. Angola: Exame Nacional 2015 da Educação para Todos. Luanda, 2014. 
BRANDÃO, C. R. O que é educação popular. 1983. Disponível em: http://ifibe.edu.br/ arq/201509112220031556922168.pdf. Acesso em: 27 mar. 2019.

BRITO NETO, M. História e educação em Angola: do colonialismo ao movimento popular de libertação de angola (MPLA). Disponível em: http://repositorio.unicamp.br/bitstream/ REPOSIP/252396/1/BritoNeto_Manuel_D.pdf. Acesso em: 27 mar. 2019.

CASTRO, E. Vocabulário de Foucault: um percurso pelos seus temas, conceitos e autores. Belo Horizonte: Autêntica, 2016. 480 p.

CHIPALANGA, S. I. Gravidez na adolescência em Angola: estudo do funcionamento familiar e satisfação com a vida. 2014. 66 f. Dissertação (Mestrado em Psicologia) - Universidade de Coimbra, Coimbra, 2014.

FERREIRA, M. J. da S. M. Educação e política em Angola: uma proposta de diferenciação social. Cadernos de Estudos Africanos [on-line], v. 7, n. 8, 2005. Doi : 10.4000/ cea.1070.

FERREIRO, E. Com todas as letras. 14. ed. São Paulo: Cortez, 2017. 104 p.

FOUCAULT, M. História da sexualidade I: a vontade de saber. Rio de Janeiro, Edições Graal, 1999. 178 p.

FOUCAULT, M. A ordem do discurso: aula inaugural no collège de France, pronunciada em 2 de dezembro de 1970. 22. ed. Tradução de Laura Sampaio. São Paulo: Edições Loyola, 2012.

FREIRE, P. Pedagogia da autonomia: saberes necessários à prática educativa. São Paulo: Paz e Terra, 1996. 144 p.

GOMES, C. A. O mito da portugalidade no ensino colonial: a história e a razão metonímica. Mulemba [on-line], Rio de Janeiro, v. 4, n. 8, 2014. Doi : 10.4000/mulemba.263.

LIBERATO, E. Avanço e retrocesso na educação em Angola. Revista Brasileira de Educação, Rio de Janeiro, v. 19, n. 59, p. 1.003-1.031, out./dez. 2014.

MARTINS, J. P. O. O Brazil e as colônias portuguesas. 5. ed. Lisboa: Livraria Editora Zamparoni, 1920. 312 p.

MEIJER, G.; BIRMINGHAM, D. Da paz militar à justiça social?: o processo de paz angolano. Londres: Conciliation Resources, 2004. 96 p.

MENDES, C.; ALVES, J. M.; CARVALHO, P. A governança educativa local: a alfabetização pelas direções províncias em Angola. Universidade Católica Portuguesa. Faculdade de Educação e Psicologia. Educação, Territórios e Desenvolvimento Humano: Atas do I Seminário Internacional,v. II - Comunicações Livres. Porto, 2015.

MICHINGI, K. M. M. As controvérsias da reforma educativa em Angola: uma análise crítica das percepções dos professores do 10 ciclo do ensino primário. 2013. 59 f. Dissertação (Mestrado em Sociologia) - Departamento de Sociologia, Instituto Universitário de Lisboa, 2013. 
NASCIMENTO, W. S. Gentes do mato: os "novos assimilados" em Luanda (1926-1961). 2013. 235 f. Tese (Doutorado em História) - Universidade de São Paulo, São Paulo, 2013.

NETO, A. Discurso da Proclamação da Independência de Angola. Luanda. Comité Central do MPLA, 1975.

NGABA, A. V. Políticas educativas em Angola (1975-2005): entre o global e o local - o sistema educativo mundial, Mbanza-Kongo: Edição Sedieca, 2012.

NGULUVE, A. Política educacional angolana (1976-2005): organização, desenvolvimento e perspectiva. 2006. 2018 f. Dissertação (Mestrado em Educação) - Faculdade de Educação, Universidade de São Paulo, São Paulo, 2006.

OBSERVATÓRIO DE ÁFRICA. Violação ao direito de gratuidade à educação em Angola. 2016. Disponível em: https://observatoriodaafrica.wordpress.com/2016/12/29/violacao-ao-direito-degratuidade-a-educacao-em-angola/. Acesso em: 27 mar. 2019.

PACAVIRA, M. Gentes do mato. Lisboa: África Editora, 1981.

PAIXÃO, V. Educação popular. Conferência realizada na Associação do Comércio de Angra do Heroísmo. Angra do Heroísmo, 1921.

PAIN, R. S. A centralização política e sua influência no desenvolvimento. Sociedade e cultura, Goiânia, v. 10, n. 2, p. 253-265, jul./dez. 2007. Doi: 10.5216/sec.v10i2.3145.

RIBAS, O. Tudo isso aconteceu. Edição? Lisboa: Luanda: Editora?, 2009.

SILVA, M. V. Alfabetização: sujeito e autoria. In: CONGRESSO BRASILEIRO DE PSICOPEDAGOGIA, 5.; CONGRESSO LATINO AMERICANO DE PSICOPEDAGOGIA; ENCONTRO BRASILEIRO DE PSICOPEDAGOGOS, 9., 2000, São Paulo. Anais [...]. São Paulo, jul. 2000.

SILVA, E. A. Educação no meio rural em Angola: tradição, (des)igualdade de género e cidadania. In: CONGRESSO LUSO AFRO BRASILEIRO DE CIÊNCIAS SOCIAIS. DIVERSIDADE E (DES) IGUALDADES, 11., 2011, Salvador. Anais [...]. Salvador: Editora da UFBA, 2011.

TRAVERSINI. C. S. Programa Alfabetização Solidária: o governamento de todos e de cada um. 2003. 210 f. Tese (Doutorado em Educação) - Universidade Federal do Rio Grande do Sul, Porto Alegre, 2003.

Submetido em 29 de novembro de 2018.

Aprovado em 1ํㅡㄹ de abril de 2019. 